\title{
Micronutrient interactions: effects on absorption and bioavailability
}

\author{
Brittmarie Sandström \\ Research Department of Human Nutrition, The Royal Veterinary and Agricultural University, \\ Rolighedsvej 30, 1958 Frederiksberg C, Denmark
}

\begin{abstract}
A potential risk of interactions between micronutrients affecting absorption and bioavailability has to be considered in any supplementation or fortification strategy. At levels of essential micronutrients present in foods, most micronutrients appear to utilise specific absorptive mechanisms and not be vulnerable to interactions. In aqueous solutions and at higher intake levels competition between elements with similar chemical characteristics and uptake by nonregulated processes can take place. These interactions have clearly been demonstrated in experimental absorption studies and to some extent have been confirmed in supplementation studies. Negative effects of iron supplementation on indices of zinc and copper status and of zinc supplementation on iron and copper status have been reported. In contrast, the negative effect of calcium on iron absorption has not been confirmed in long-term supplementation studies. Ascorbic acid has a strong iron absorption promoting potential and in iron deficient populations ascorbic acid supplementation improves iron status. Thus, ascorbic acid supplements or an increased intake of ascorbic acid rich foods could have important public health implications, especially in populations subsisting on a mainly plant food based diet. The effect of poor status of a given micronutrient on absorption and utilisation of other micronutrients should also be considered while developing strategies to improve micronutrient status in a population. Awareness of these interactions, combined with a balanced evaluation of the dietary intake of the population with regard to absorption promoting and inhibiting substances and the risk for multiple deficiencies, could lead to more effective strategies to improve micronutrient status.
\end{abstract}

\section{Iron: Zinc: Copper: Ascorbic acid: Interactions}

\section{Introduction}

Micronutrient interactions can affect absorption and bioavailability by a number of mechanisms. Minerals with chemical similarities can compete for transport proteins or other uptake mechanisms, as well as for chelating organic substances, facilitating or hindering absorption. The quantitative consequences of these interactions will depend on the relative concentrations of the nutrients. At normal dietary concentrations the absorption of most minerals is active or saturable, while at higher intakes passive diffusion can take place. A poor nutritional status with regard to vitamins affects mucosal integrity and can thereby affect absorption of other nutrients. In a similar way trace element deficiencies could affect general absorptive capacity, as well as specific mechanisms needed for uptake of other micronutrients.

\section{Iron-zinc interactions}

The widespread use of iron fortification and supplementation makes any interaction between iron and other micronutrients of special nutritional relevance. Single meal studies have demonstrated that when given as an aqueous solution, a situation similar to intake of supplemental iron, the absorption of zinc was reduced by iron in a dose-dependent way (Sandström et al. 1985) (Table 1). However, when iron was added to solid foods or infant formula, no effect on zinc absorption in adults was observed (Sandström et al. 1985; Davidsson et al. 1995). Population groups with higher zinc requirements, such as infants, adolescents, and pregnant and lactating women, may be more sensitive to iron-zinc interactions. Iron fortification of an infant milk formula (40 mg Fe/100 g) resulted in lower plasma zinc concentrations than in a control group given a commercially available formula containing $8.3 \mathrm{mg}$ iron/100 g (Power et al. 1991). Decreased serum zinc concentrations have been reported after iron supplementation with doses $>60 \mathrm{mg} / \mathrm{d}$ (Hambidge et al. 1983; Breskin et al. 1983; Hambidge et al. 1987; O'Brien et al. 1999), but also at a level of supplementation of only $18 \mathrm{mg} / \mathrm{d}$ in pregnant teenagers (Dawson et al. 1989). In contrast, Sheldon et al. (1985) reported no effects of iron supplements on serum zinc 
Table 1. Examples of mineral-mineral interactions affecting absorption

\begin{tabular}{|c|c|c|c|c|c|c|}
\hline Zinc $\mu \mathrm{mol}$ & Iron $\mu \mathrm{mol}$ & Manganese $\mu \mathrm{mol}$ & Form of dosage & Zinc absorption \% & Iron absorption \% & Reference \\
\hline 40 & 0 & & Water & 74 & - & (Sandström et al. 1985) \\
\hline 40 & 40 & & Water & 58 & - & (Sandström et al. 1985) \\
\hline 40 & 1000 & & Water & 34 & - & (Sandström et al. 1985) \\
\hline 40 & 40 & & Solid meal & 25 & - & (Sandström et al. 1985) \\
\hline 40 & 1000 & & Solid meal & 22 & - & (Sandström et al. 1985) \\
\hline 8 & 1 & & Infant formula & - & 39 & (Davidsson et al. 1995) \\
\hline 8 & 96 & & Infant formula & - & 42 & (Davidsson et al. 1995) \\
\hline 0 & 53 & & Water & - & 23 & (Rossander-Hultén et al. 1991) \\
\hline 229 & 53 & & Water & - & 12 & (Rossander-Hultén et al. 1991) \\
\hline $\mathrm{NA}^{*}$ & 53 & & Solid meal & - & 11 & (Rossander-Hultén et al. 1991) \\
\hline $229 \dagger$ & 53 & & Solid meal & - & 12 & (Rossander-Hultén et al. 1991) \\
\hline 0 & 53 & 0 & Water & - & 31 & (Rossander-Hultén et al. 1991) \\
\hline 0 & 53 & 254 & Water & - & 18 & (Rossander-Hultén et al. 1991) \\
\hline NA & 53 & 0 & Solid meal & - & 14 & (Rossander-Hultén et al. 1991) \\
\hline NA & 53 & $254^{\dagger}$ & Solid meal & - & 8 & (Rossander-Hultén et al. 1991) \\
\hline
\end{tabular}

* NA not analysed.

† Added to solid meal content.

concentrations during pregnancy. The limitations of serum zinc as an indicator of body zinc status make it difficult to identify under what physiological as well as dietary conditions negative effects of a high iron intake on zinc absorption and utilisation are likely to occur. In addition, systematic dose-response studies to identify the level of intake, which could impose a risk for interactions are lacking.

Similar to the iron-zinc interaction, zinc in high doses in aqueous solutions impairs iron absorption, while no effect is observed when zinc is added to meals (Rossander-Hultén et al. 1991). These results suggest that in the presence of organic substances iron and zinc are absorbed by different mechanisms and that the risk for interactions is larger when the nutrients are provided as supplements. In contrast, manganese affects iron absorption in a way that indicates that the intestine cannot differentiate between manganese and iron (Rossander-Hultén et al. 1991). A high manganese intake, as could be the case in tea drinking populations, may therefore impose a risk of reduced iron utilisation.

\section{Calcium interactions}

An absorption depressing effect of calcium on iron absorption has been clearly demonstrated in single-meal studies and short-term diet intervention studies (Hallberg et al. 1991). An addition of $150 \mathrm{mg}$ of calcium to bread or a hamburger meal reduced iron absorption by $50 \%$. The interaction is suggested to take place within the mucosal cells as both haem and nonhaem iron is affected (Hallberg et al. 1993). Long-term calcium supplementation studies have, however, failed to demonstrate any negative effect on iron status (Ilich-Ernst et al. 1998; Kalkwarf \& Harrast, 1998; Minihane \& Fairweather-Tait, 1998; Sokoll \& Dawson-Hughes, 1992; Yan et al. 1996). Treatment of adolescent girls with $1000 \mathrm{mg}$ of calcium per day over 4 years did not have negative effects on iron status (IlichErnst et al. 1998).

Calcium does not seem to have a direct effect on zinc absorption (Spencer et al. 1984). Animal studies have demonstrated that in the presence of phytate, calcium impairs zinc absorption, probably by co-precipitation with phytate and zinc (Oberleas et al. 1966). Absorption studies in humans suggest that the effect of calcium on zinc availability at nutritionally relevant concentrations is less pronounced and that calcium addition may even improve zinc absorption from phytate containing foods (Lönnerdal et al. 1984; Petterson et al. 1994). A negative interaction is, however, possible at higher calcium intake, e.g. with lime treatment of corn and intake of calcium supplements.

\section{Zinc-copper-iron interactions}

Copper is essential for iron transport between tissues and one of the signs of copper deficiency is microcytic hypochromic anaemia. Zinc supplementation $(50 \mathrm{mg} / \mathrm{d}$ for $10 \mathrm{wk}$ ) in adult females reduced indices of iron and copper status (Yadrick et al. 1989). Addition of iron $(50 \mathrm{mg} / \mathrm{d}$ ) ameliorated the effects on iron but not on copper status. A similar decrease in copper status has been observed in men given $25 \mathrm{mg}$ zinc for 6 weeks (Fischer et al. 1984). Cases of microcytic hypochromic anaemia after long-term zinc supplementation have also been reported (Broun et al. 1990; Hoogenraad et al. 1985). The zinc-copper interaction probably takes place at the absorption level. Within the range of typical dietary levels of zinc copper absorption is, however, only marginally decreased at higher zinc intakes (Turnlund et al. 1988).

\section{Vitamin-mineral interactions}

Vitamin $\mathrm{C}$ is a strong promoter of iron absorption from the diet (Hallberg et al. 1986) and can counteract the inhibitory effects of dietary phytate and tannins. Some supplementation studies have confirmed a positive effect of vitamin C on iron status, while less consistent results are found in other studies. The impact of vitamin $\mathrm{C}$ is apparently dependent on the characteristics of the habitual diet. In anaemic children in India, significant increases in haemoglobin levels were observed after an intake of $200 \mathrm{mg}$ ascorbic acid daily for 60 days (Seshadri et al. 1985). In children with mild iron deficiency anaemia who are 
consuming a plant-based diet with a low dietary vitamin $\mathrm{C}$ and iron intake, an additional $50 \mathrm{mg}$ of vitamin $\mathrm{C} / \mathrm{d}$ improved iron status over an 8-week period (Mao \& Yao, 1992). In adults, $500 \mathrm{mg}$ ascorbic acid given to strict vegetarians improved iron status after 2 months (Sharma \& Mathur, 1995), while $2 \mathrm{~g}$ of vitamin $\mathrm{C}$ given to subjects consuming a meat containing diet had no effect on iron status (Cook et al. 1984). Locally available, ascorbate rich foods could be an alternative to supplementation for enhancing absorption of dietary iron. It has, however, been suggested that long-term vitamin $\mathrm{C}$ supplementation may impair the absorption of copper and thereby counteract the positive effect on iron absorption. The effects of ascorbic acid on copper absorption are, however, not conclusive (Finley \& Cerklewski, 1983; Jacob et al. 1987). Vitamin C appears to affect selenium availability both positively and negatively depending on chemical form and dietary conditions (Levander, 1987; Robinson et al. 1985), while zinc absorption seems to be unaffected (Sandström \& Cederblad, 1987). Recent studies suggest that vitamin A and $\beta$-carotene can enhance nonhaem iron absorption, and thereby contribute to an increase in haemoglobin levels (Garcia-Casal et al. 1998).

\section{Interactions related to micronutrient status}

Other interactions between vitamins and minerals are related to general effects on nutritional status. The polyglutamine forms of dietary folate require the conjugation by a zinc-dependent hydrolase prior to intestinal absorption. Zinc deficiency could consequently impair folate bioavailability. This has not systematically been addressed in humans. In subjects with presumably normal zinc status, variations in zinc intake do not affect folate utilisation (Kauwell et al. 1995). It has also been suggested that folate could impair zinc absorption. However, neither an effect of folate status on zinc absorption or of short-term folate supplementation on zinc absorption has been convincingly demonstrated in humans (Kauwell et al. 1995; Milne, 1989). Furthermore, folic acid supplementation in pregnancy appears to have no adverse affects on maternal zinc nutriture and pregnancy outcome (Tamura et al. 1992). Animal studies suggest that riboflavin deficiency affects iron absorption by reducing the absorptive capacity of the gastrointestinal villi. However, studies among humans have failed to demonstrate significant changes in iron absorption following riboflavin supplementation (Fairweather-Tait et al. 1992; Powers, 1995).

Iron deficiency does not only increase the efficiency of iron absorption, it seems to affect absorption of chemically related elements such as manganese (Mena et al. 1969) and possibly also toxic elements (Wright et al. 2000). Zinc deficiency, on the other hand, leads to mucosal dystrophy, which could reduce absorption, not only of the polyglutamine forms of folate, but also of other nutrients. A poor zinc status will also affect the utilisation of vitamin $\mathrm{A}$, because zinc containing proteins are needed for the release of vitamin A from liver and for the tissue metabolism of vitamin A. In a recent study, supplementation with $20 \mathrm{mg}$ zinc per day or in combination with $20 \mathrm{mg}$ iron per day improved indicators of vitamin A status in Mexican children aged 18-36 months (Munoz et al. 2000). Similarly, supplementation with $40 \mathrm{mg}$ zinc daily for 5-10 days in malnourished children resulted in a significant increase in plasma vitamin $\mathrm{A}$ and retinol binding protein (Shingwekar et al. 1979).

\section{Research needs}

To reveal the risk for and consequences of interactions between micronutrients, basic molecular and experimental research is needed regarding the mechanisms for and regulation of absorption and utilisation. Systematic doseresponse intervention studies in humans of nutrients can identify early biochemical or other markers of negative effects and help establish the optimal combination of nutrients. Whenever possible these studies should be undertaken in subjects with high needs of the nutrients of interest. In population intervention studies with fortified foods or supplements using single or selected nutrients, the effect on indices of status of other nutrients should be monitored and the impact of the nutritional composition of the habitual diet evaluated.

\section{Conclusions}

A number of interactions between micronutrients could take place when high doses of a single nutrient is given or when the supply of an individual micronutrient is inadequate. These potential risks for interactions have to be taken into account when food fortification or supplementation programmes are initiated, especially when directed to population groups with high micronutrient requirements. The interactions between iron, zinc and copper appear to be especially important. In populations where the major reason for iron deficiency is a poor availability of iron from the diet, there is also a risk for marginal zinc status especially in growing individuals. Iron supplementation could then impose a potential risk for negative effects not only on growth and development but also on other functions such as immune defence through an impaired zinc status. In a similar way, zinc supplementation may affect copper dependent iron metabolism and immune functions. Systematic studies of these interactions and of the advantages and disadvantages of different approaches to improve micronutrient status in populations are warranted.

\section{References}

Breskin MW, Worthington-Roberts BS, Knopp RH, Brown Z, Plovie B, Karle Mottet N \& Mills JL (1983) First trimester serum zinc concentrations in human pregnancy. American Journal of Clinical Nutrition 38, 943-953.

Broun ER, Greist A, Tricot G \& Hoffman R (1990) Excessive zinc ingestion. Journal of the American Medical Association 264, $1441-1443$.

Cook JD, Watson SS, Simpson KM, Lipschitz DA \& Skikne BS (1984) The effect of high ascorbic acid supplementation on body iron stores. Blood 64, 721-726.

Davidsson L, Almgren A, Sandström B \& Hurrell RF (1995) Zinc absorption in adult humans: the effect of iron fortification. British Journal of Nutrition 74, 417-425. 
Dawson EB, Albers J \& McGanity WJ (1989) Serum zinc changes due to iron supplementation in teenage pregnancy. American Journal of Clinical Nutrition 50, 848-852.

Fairweather-Tait SJ, Powers HJ, Minski MJ, Whitehead J \& Downes R (1992) Riboflavin deficiency and iron absorption in adult Gambian men. Annals of Nutrition \& Metabolism 36, 3440.

Finley EB \& Cerklewski FL (1983) Influence of ascorbic acid supplementation on copper status in young adult men. American Journal of Clinical Nutrition 37, 553-556.

Fischer PWF, Giroux A \& L'Abbé MR (1984) Effect of zinc supplementation on copper status in adult man. American Journal of Clinical Nutrition 40, 743-746.

Garcia-Casal MN, Larysse M, Solano L, Baron MA, Arguello F, Llovera D, Ramirez J, Leets I \& Tropper E (1998) Vitamin A and beta-carotene can improve nonheme iron absorption from rice, wheat and corn by humans. Journal of Nutrition 128, 646-650.

Hallberg L, Brune M \& Rossander L (1986) Effect of ascorbic acid on iron absorption from different types of meal. Studies with ascorbic-acid-rich foods and synthetic ascorbic acid given in different amounts with different meals. Human Nutrition: Clinical Nutrition 40, 97-113.

Hallberg L, Brune M, Erlandsson M, Sandberg A-S \& RossanderHultén L (1991) Calcium: effect of different amounts on nonheme- and heme-iron absorption in humans. American Journal of Clinical Nutrition 53, 112-119.

Hallberg L, Rossander-Hultén L, Brune M \& Gleerup A (1993) Inhibition of haem-iron absorption in man by calcium. British Journal of Nutrition 69, 533-540.

Hambidge KM, Krebs NF, Jacobs MA, Favier A, Guyette L \& Ikle DN (1983) Zinc nutritional status during pregnancy: a longitudinal study. American Journal of Clinical Nutrition 37, 429-442.

Hambidge KM, Krebs NF, Sibley L \& English J (1987) Acute effects of iron therapy on zinc status during pregnancy. Obstetrics \& Gynaecology 70, 593-596.

Hoogenraad TU, Dekker AW \& Van Den Hamer CJA (1985) Copper responsive anemia, induced by oral zinc therapy in a patient with acrodermatitis enteropathica. The Science of the Total Environment 42, 37-43.

Ilich-Ernst JZ, McKenna AA, Badenhop NE, Clairmont AC, Andon MB, Nahhas RW, Goel P \& Matkovic V (1998) Iron status, menarche, and calcium supplementation in adolescent girls. American Journal of Clinical Nutrition 68, 880-887.

Jacob RA, Skala JH, Omaye ST \& Turnlund JR (1987) Effect of varying ascorbic acid intakes on copper absorption and ceruloplasmin levels in young men. Journal of Nutrition 117, 2109-2115.

Kalkwarf HJ \& Harrast SD (1998) Effects of calcium supplementation and lactation on iron status. American Journal of Clinical Nutrition 67, 1244-1249.

Kauwell GPA, Bailey LB, Gregory JFI, Bowling DW \& Cousins RJ (1995) Zinc status is not adversely affected by folic acid supplementation and zinc intake does not impair folate utilization in human subjects. Journal of Nutrition 125, $66-72$.

Levander OA (1987) A global view of human selenium nutrition. Annual Review of Nutrition 7, 227-250.

Lönnerdal B, Cederblad Å, Davidsson L \& Sandström B (1984) The effect of individual components of soy formula and cows' milk formula on zinc bioavailability. American Journal of Clinical Nutrition 40, 1064-1070.

Mao X \& Yao G (1992) Effect of vitamin C supplementations on iron deficiency anemia in Chinese children. Biomedical Environmental Science 5, 125-129.

Mena I, Horiuchi K, Burke K \& Cotzias GC (1969) Chronic manganese poisoning. Individual susceptibility and absorption of iron. Neurology 19, 1000-1006.

Milne DB (1989) Effects of folic acid supplements on zinc-65 absorption and retention. The Journal of Trace Elements in Experimental Medicine 2, 297-304.

Minihane AM \& Fairweather-Tait SJ (1998) Effect of calcium supplementation on daily nonheme-iron absorption and longterm iron status. American Journal of Clinical Nutrition $\mathbf{6 8}$, 96-102.

Munoz EC, Rosado JL, Lopez P, Furr HC \& Allen LH (2000) Iron and zinc supplementation improves indicators of vitamin A status of Mexican preschoolers. American Journal of Clinical Nutrition 71, 789-794.

Oberleas D, Muhrer ME \& O'Dell BL (1966) Dietary metalcomplexing agents and zinc availability in the rat. Journal of Nutrition 90, 56-62.

O'Brien KO, Zavaleta N, Caulfield LE, Yang D-X \& Abrams SA (1999) Influence of prenatal iron and zinc supplements on supplemental iron absorption, red blood cell iron incorporation, and iron status in pregnant Peruvian women. American Journal of Clinical Nutrition 69, 509-515.

Petterson DS, Sandström B \& Cederblad Å (1994) Absorption of zinc from lupin (Lupinus angustifolius)-based foods. British Journal of Nutrition 72, 865-871.

Power HM, Heese HD, Beatty DW, Hughes J \& Dempster WS (1991) Iron fortification of infant milk formula: the effects on iron status and immune function. Annals of Tropical Paediatrics 11, 57-66.

Powers HJ (1995) Riboflavin-iron interactions with particular emphasis on the gastrointestinal tract. Proceedings of the Nutrition Society 54, 509-517.

Robinson MF, Thomson CD \& Huemmer PK (1985) Effect of a megadose of ascorbic acid, a meal and orange juice on the absorption of selenium as sodium selenite. The New Zealand Medical Journal 98, 627-629.

Rossander-Hultén L, Brune M, Sandström B, Lönnerdal B \& Hallberg L (1991) Competitive inhibition of iron absorption by manganese and zinc in humans. American Journal of Clinical Nutrition 54, 152-156.

Sandström B, Davidsson L, Cederblad ̊̊ \& Lönnerdal B (1985) Oral iron, dietary ligands and zinc absorption. Journal of Nutrition 115, 411-414.

Sandström B \& Cederblad A (1987) Effect of ascorbic acid on the absorption of zinc and calcium in man. International Journal of Vitamin \& Nutrition Research 57, 87-90.

Seshadri S, Shah A \& Bhade S (1985) Haematologic response to anaemic preschool children to ascorbic acid supplementation. Human Nutrition: Applied Nutrition 39, 151-154.

Sharma DC \& Mathur R (1995) Correction of anaemia and iron deficiency in vegetarians by administration of ascorbic acid. Indian Journal of Physiological Pharmacology 39, 403-406.

Sheldon WL, Aspillaga MO, Smith PA \& Lind T (1985) The effects of oral iron supplementation on zinc and magnesium levels during pregnancy. British Journal of Obstretics and Gynaecology 92, 892-898.

Shingwekar AG, Mohanram M \& Reddy V (1979) Effect of zinc supplementation on plasma levels of vitamin A and retinolbinding protein in malnourished children. Clinica Chimica Acta 93, 97-100.

Sokoll LJ \& Dawson-Hughes B (1992) Calcium supplementation and plasma ferritin concentrations in premenopausal women. American Journal of Clinical Nutrition 56, 1045-1048.

Spencer H, Kramer L, Norris C \& Osis D (1984) Effect of calcium and phosphorus on zinc metabolism in man. American Journal of Clinical Nutrition 40, 1213-1218.

Tamura T, Goldenberg RL, Freeberg LE, Cliver SP, Cutter GR \& Hoffman HJ (1992) Maternal serum folate and zinc 
concentrations and their relationships to pregnancy outcome. American Journal of Clinical Nutrition 56, 365-370.

Turnlund JR, Wada L, King JC, Keyes WR \& Acord LL (1988) Copper absorption in young men fed adequate and low zinc diets. Biological Trace Element Research 17, 31-41.

Wright RO, Shannon MW, Wright RJ \& Hu H (2000) Association between iron deficiency and low-level lead poisoning in an urban primary care clinic. American Journal of Public Health 89, 1049-1053.
Yadrick MK, Kenney MA \& Winterfeldt EA (1989) Iron, copper, and zinc status: response to supplementation with zinc or zinc and iron in adult females. American Journal of Clinical Nutrition 49, 145-150.

Yan L, Prentice A, Dibba B, Jarjou LMA, Stirling DM \& Fairweather-Tait S (1996) The effect of long-term calcium supplementation on indices of iron, zinc and magnesium status in lactating Gambian women. British Journal of Nutrition 76, $821-831$ 